\title{
Efeito prebiótico do mel sobre o crescimento e viabilidade de Bifidobacterium spp. e Lactobacillus spp. em leite
}

\author{
Prebiotic effect of honey on growth and viability of Bifidobacterium spp. and Lactobacillus spp. in milk
}

\author{
Lívia Nolasco MACEDO ${ }^{1}$, Rosa Helena LUCHESE ${ }^{1 *}$, André Fioravante GUERRA¹, Celso Guimarães BARBOSA²
}

\begin{abstract}
Resumo
Para ser considerado prebiótico, um microrganismo deve atender a uma série de requisitos, sendo a manutenção da viabilidade, um dos principais. Culturas probióticas de Lactobacillus spp. e Bifidobacterium spp. foram cultivadas em leite em pó desnatado reconstituído $12 \%$ adicionado de $3 \%(\mathrm{p} / \mathrm{v})$ de mel pasteurizado. Foram preparados controles sem mel. Todos os cultivos mantiveram-se viáveis por 46 dias a $7{ }^{\circ} \mathrm{C}$ atendendo o número mínimo exigido pela legislação. O maior número de células viáveis de L. casei-01 e L. casei Shirota (>9,0 log $\log _{10} \mathrm{UFC}_{\mathrm{mL}}^{-1}$ ) foi observado nos cultivos contendo mel. A acidez titulável produzida por estas culturas foi de 1,44\%. O número de células viáveis de L. acidophilus $\mathrm{Sacco}^{\circ}$ aos 46 dias em cultivos com mel foi significativamente maior $(\mathrm{p}<0,05)$ que nos controles. Considerando todo o período de estocagem, o mel exerceu efeito positivo significativo $(\mathrm{p}<0,05)$ apenas para as culturas de Bifidobacterium. O menor crescimento e a menor acidificação no $46^{\circ}$ dia foram observados nos cultivos de $B f$. lactis Bb-12, sendo de 7,63 $\log _{10} \mathrm{UFC}_{\mathrm{mL}} \mathrm{mL}^{-1}$ e,61\% de acidez em presença de mel e $6,11 \log _{10}$ UFC. $\mathrm{mL}^{-1}$ e $0,30 \%$ de acidez nos controles. Diferentemente, os cultivos de $B f$. lactis Sacco atingiram contagens de $9,11 \log _{10}$ UFC. $\mathrm{mL}^{-1}$ e produziram $1,11 \%$ de acidez.
\end{abstract}

Palavras-chave: culturas probióticas; leite fermentado; mel de assa peixe.

\begin{abstract}
To be considered prebiotic, a microorganism must fulfill a series of requirements and the maintenance of viability is a major one. Probiotic cultures of Lactobacillus spp. and Bifidobacterium spp. were cultured in $12 \%(\mathrm{w} / \mathrm{v})$ reconstituted nonfat dry milk containing $3 \%$ (w/v) of pasteurized honey. Controls without honey were prepared. All cultures remained viable for up 46 days at $7{ }^{\circ} \mathrm{C}$ conforming to the regulation requirement. The higher cell number of $L$. casei-01 and L. casei Shirota $\left(>9.0 \log 10\right.$ CFU.mL $\left.{ }^{-1}\right)$ were maintained in the presence of honey. The titratable acidity produced by these cultures was of $1.44 \%$. On the $46^{\text {th }}$ day of storage, the number of L. acidophilus Sacco ${ }^{\circledR}$ viable cells in the presence of honey was significantly higher $(\mathrm{p}<0.05)$ compared to the control. Considering the overall storage period, honey exerted significant positive effect $(\mathrm{p}<0,05)$ only on Bifidobacterium cultures. The lowest growth and acidity on the $46^{\text {th }}$ day was observed with Bf. Lactis Bb12, being 7,63 $\log _{10}$ CFU.g ${ }^{-1}$ and $0,61 \%$ of acidity in the presence of honey and $6.11 \log \mathrm{CFU} \cdot \mathrm{mL}^{-1}$ and $0,30 \%$ of acidity in the control. Differently, Bf. lactis Sacco ${ }^{\circledast}$ cultures reached counts of $9,11 \log _{10}$ CFU.mL ${ }^{-1}$ and produced $1.11 \%$ acidity.

Keywords: probiotic cultures; fermented milk; assa peixe honey.
\end{abstract}

\section{Introdução}

Alimento funcional é todo alimento que oferece um efeito benéfico, além do valor nutritivo inerente à sua composição química podendo contribuir na prevenção e tratamento de doenças (ANJO, 2004). Os probióticos são definidos como uma cultura simples ou mista de microrganismos vivos, os quais beneficiam o homem ou os animais por meio da melhoria das propriedades da microbiota intestinal (HOLZAPFEL; SCHILLINGER, 2002). Os prebióticos são componentes alimentares não digeríveis que afetam beneficamente o hospedeiro, por estimularem seletivamente a proliferação ou atividade de populações de bactérias desejáveis no cólon. Adicionalmente, o prebiótico pode inibir a multiplicação de patógenos, garantindo benefícios adicionais à saúde do hospedeiro (SAAD, 2006).

Dentre os principais prebióticos que têm recebido maior atenção, destacam-se a inulina e os oligossacarídeos, especial- mente os frutooligossacarídeos (USTUNOL, 2005). Os oligossacarídeos são açúcares encontrados como componentes naturais em muitos alimentos como frutas, vegetais, leite e mel. (LEITE et al., 2000; NAKANO, 1998). Crittenden e Playne (1996) definem os oligossacarídeos como glicosídeos que contêm entre três e dez monossacarídeos. Entretanto outros autores definem oligossacarídeos como carboidratos que possuem um baixo grau de polimerização (de 2 a 20) e conseqüentemente, baixo peso molecular (ROBERFROID; SLAVIN, 2000).

Segundo Anjo (2004), o mel é um alimento funcional que exerce a atividade prebiótica e tem como efeito, a regulação do trânsito intestinal, regulação da pressão arterial, redução do risco de câncer e dos níveis de colesterol.

Recebido para publicação em 26/7/2007

Aceito para publicação em 30/4/2008 (002712)

${ }^{1}$ Departamento de Matemática e Estatística, Universidade Federal Rural do Rio de Janeiro - UFRRJ, CEP 23890-000, Seropédica - RJ, Brasil, E-mail: rhluche@ufrrj.br

${ }^{2}$ Departamento de Tecnologia de Alimentos, Universidade Federal Rural do Rio de Janeiro - UFRRJ, CEP 23890-000 Seropédica - RJ, Brasil

${ }^{*}$ A quem a correspondência deve ser enviada 
A indústria de laticínios está entre as que apresentam maior crescimento na disponibilização de produtos funcionais, em especial iogurte, bebidas à base de soro de leite, e outros leites fermentados, em que essa funcionalidade é efetivada por meio da utilização de culturas probióticas e/ou adição de substâncias prebióticas, como por exemplo, oligossacarídeos (BRANDÃO, 2002; SAARELA et al., 2000). Entretanto, o uso de algumas culturas probióticas em leites fermentados é limitado, devido às substâncias produzidas por estes microrganismos, as quais podem ocasionar sabores estranhos ou off-flavors nos produtos finais, além da sensibilidade a uma série de fatores, como $\mathrm{pH}$ ácido e a presença de oxigênio (KAILASAPATHY; RYBKA, 1997; SHAH, 2000).

Várias espécies de bactérias lácticas são utilizadas comercialmente para a produção de leites fermentados, produtos cárneos, iogurtes, queijos, salames, picles, entre outros. Alguns produtos lácteos fermentados com bactérias lácticas têm sido utilizados no tratamento de doenças do trato gastrintestinal como: intolerância à lactose, gastrenterites agudas, efeitos adversos da radioterapia, constipação, alergias alimentares, entre outras (FONDÉN et al., 2000).

As espécies pertencentes ao gênero Lactobacillus, crescem em temperaturas que variam de 2 a $53^{\circ} \mathrm{C}$, com valores ótimos, geralmente de 30 a $40^{\circ} \mathrm{C}$. São acidúricos, com pH ótimo entre 5,5 e 6,2 sendo que o crescimento pode ocorrer em $\mathrm{pH} 5,0$ ou menor. $\mathrm{O}$ crescimento é freqüentemente reduzido em meios neutros ou alcalinos (KANDLER; WEISS, 1986).

As espécies do gênero Bifidobacterium, são heterofermentativas, produzindo ácido acético e láctico na proporção molar de 3:2. A temperatura ótima de crescimento oscila entre $37-41^{\circ} \mathrm{C}$. Em relação ao $\mathrm{pH}$ ótimo, verificam-se valores entre 6,0 e 7,0 com ausência de crescimento a valores de $\mathrm{pH}$ ácidos de 4,5-5,0 ou valores de $\mathrm{pH}$ alcalinos de 8,0-8,5 (RASIC; KURMANN, 1983; DANONE, 1997). Entretanto, foi verificado em estudo realizado por Boylston et al., (2004) que, sob condições típicas de digestão, nas quais o $\mathrm{pH}$ varia de 1,5 a 3,0, espécies como Bifidobacterium longum 1971 e Bifidobacterium pseudolongum 20097 foram tolerantes às condições ácidas quando comparadas às outras 7 linhagens pesquisadas. Foi observado que, após 3 horas de incubação, a contagem dessas duas linhagens ácidotolerantes decresceu menos que 1 ciclo logarítmico, enquanto a contagem das células viáveis das outras linhagens analisadas decresceu até 7 ciclos logarítmicos.

A legislação brasileira preconiza contagem mínima de $10^{7} \mathrm{UFC} . \mathrm{mL}^{-1}$ para leite acidófilo e $10^{6} \mathrm{UFC} . \mathrm{mL}^{-1}$ para leite fermentado ou cultivado na hora de serem consumidos (BRASIL, 2000).

Segundo Ferreira (1996), os maiores problemas com bactérias bífidas em laticínios são as suas características de anaerobiose e exigências de grande porcentagem de inóculo, em torno de $10 \%$. Gomes e Malcata (1999) relatam que os produtos fermentados na hora de serem consumidos devem conter no mínimo $10^{6} \mathrm{UFC} \cdot \mathrm{mL}^{-1}$ de células probióticas viáveis, devido à dose mínima terapêutica diária ser de $10^{8}-10^{9}$ células viáveis em $100 \mathrm{~g}$ do produto fermentado. Entretanto, Shah et al., (1995) sugerem que, para efeito terapêutico, o produto deve conter $\geq 10^{5}$ células/mL. Já para Vinderola et al., (2000) o consumo de $10^{8}-10^{11} \mathrm{UFC} /$ dia é o recomendável para alcançar os benefícios propostos pelos microrganismos probióticos.
Entretanto, vários fatores como acidificação do produto final, ácidos produzidos durante o armazenamento, nível de oxigênio no produto, permeação do oxigênio através da embalagem, compostos antimicrobianos e a perda de nutrientes do leite podem reduzir a viabilidade e, conseqüentemente, as propriedades probióticas das culturas serão prejudicadas (ANDRIGHETTO; GOMES, 2003).

A seleção de culturas probióticas destinadas à alimentação humana deve atender ao requisito de serem isoladas do trato gastrintestinal, pois geralmente são mais adaptadas às necessidades fisiológicas do homem e podem colonizar mais facilmente o intestino do que culturas originárias do cólon de animais (KURMANN, 1998).

Dentre as bactérias pertencentes ao gênero Bifidobacterium, cinco têm despertado maior interesse para a produção de leite fermentado com uso terapêutico. São elas, B. longum, B. bifidum, $B$. breve, $B$. infantis e $B$. adolescentis (TAMIME; MARSHALL; ROBINSON, 1995). Segundo Gomes, Malcata e Klaver (1998a) e Gomes, Teixeira e Malcata (1998b), produtos fermentados com bifidobactérias de origem animal apresentam a vantagem de serem mais facilmente cultivadas e resistirem às condições adversas durante o processamento, como baixo $\mathrm{pH}$ e níveis baixos de oxigênio. Esses autores relatam que a espécie B. lactis é uma das mais promissoras, pois possui boa tolerância ao oxigênio e ao ácido.

O presente estudo teve como objetivo estudar o efeito do mel de Apis mellifera sobre o crescimento e a viabilidade de culturas probióticas em leite fermentado durante 46 dias de armazenamento a $7^{\circ} \mathrm{C}$.

\section{Material e métodos}

\subsection{Materiais}

$\mathrm{Mel}$

Foi preparada uma solução com $50 \%$ p/v mel de Apis mellifera florada assa-peixe e, posteriormente, pasteurizada a $78^{\circ} \mathrm{C}$ por 6 minutos em banho-maria, utilizando frasco testemunho. Segundo os autores Gonnet, Lavie e Louveaux, (1964), o binômio tempo/temperatura de $78^{\circ} \mathrm{C} / 6^{\prime}$ é uma boa condição de pasteurização para eliminar patógenos no mel.

\section{Microrganismos probióticos}

Foram utilizadas as seguintes culturas probióticas: Lactobacillus acidophilus La-5, Lactobacillus casei-01 e Bifidobacterium Bb-12, doadas pela Christian Hansen ${ }^{\star}$, Lactobacillus acidophilus e Bifidobacterium lactis doadas pela Sacco ${ }^{\circledast}$ e Lactobacillus casei Shirota isolada da bebida láctea comercial Yakult.

\subsection{Métodos}

\section{Preparação dos leites fermentados}

Leite desnatado reconstituído a 12\% (Molico, Nestlé) foi esterilizado a $121^{\circ} \mathrm{C}$ por 10 minutos. Os frascos contendo $200 \mathrm{~mL}$ 
de leite foram adicionados de volume suficiente da solução de mel a $50 \%$ de forma a obter uma concentração final de $3 \%$. Os frascos foram inoculados separadamente com $2 \%$ das culturas probióticas em leite.

Inicialmente as culturas foram reativadas por três transferências sucessivas em leite em pó desnatado reconstituído a $12 \%$, incubadas a $36^{\circ} \mathrm{C}$ por até 72 horas em atmosfera normal, tanto as linhagens de bifidobactérias como as de lactobacilos.

Foram preparados frascos controles para cada cultura, ou seja, sem adição de mel, acrescidos com água destilada estéril em volume igual ao empregado com solução de mel. Em seguida, os frascos foram incubados a $36^{\circ} \mathrm{C}$ por 24 horas. Foi determinado o prazo de 24 horas para o término da fermentação, uma vez que as culturas comportam-se de formas diferentes. O tempo de 24 horas para a fermentação foi caracterizado como tempo zero (o) e, após este período, os frascos foram mantidos a temperatura de $7^{\circ} \mathrm{C}$ por até 46 dias, sendo avaliados nos seguintes intervalos de tempo: 0; 23; 35; e 46 dias quanto ao $\mathrm{pH}$, acidez titulável e determinação da viabilidade. Esse experimento foi repetido por três vezes.

\section{Determinação de pH e acidez dos leites fermentados}

$\mathrm{O}$ pH foi determinado utilizando o potenciômetro $300 \mathrm{M}$ da marca Analyser ${ }^{\circledast}$. A acidez titulável foi determinada de acordo com a metodologia da Federação Internacional de Laticínios (FIL) (1991).

\section{Quantificação dos microrganismos}

Para verificar a viabilidade dos microrganismos e a influência do mel sobre o seu crescimento, foram realizadas diluições seriadas até $10^{-6}$ em $9 \mathrm{~mL}$ de água peptonada $0,1 \%$ $\left(\right.$ MicroMed $^{\circledast}$ ) sendo a primeira diluição $10^{-1} \mathrm{em} 90 \mathrm{~mL}$ de água peptonada estéril.

Em seguida, foram semeadas pelo método em superfície em ágar MRS (Himedia ${ }^{\circledast}$ ) acrescido de 0,05\% de cisteína (Vetec ${ }^{\circledast}$ ) e espalhado com alça de Drigalsky. Posteriormente, foram incubadas a $36^{\circ} \mathrm{C}$ por 72 horas dentro de sacos plásticos nos quais o oxigênio foi removido parcialmente por meio de bomba manual para as culturas de lactobacilos e em jarra de anaerobiose utilizando o sistema de geração de atmosfera anaeróbia (Anaerobac ${ }^{\circledR}$, Probac do Brasil) para as bifidobactérias. Os resultados foram expressos em $\log _{10}$.UFC. $\mathrm{mL}^{-1}$.

\section{Resultados e discussão}

Um microrganismo para ser considerado probiótico deve atender a uma série de requisitos, sendo a viabilidade um dos principais. As células viáveis do(s) probiótico(s) devem estar presentes em concentrações mínimas exigidas até o momento de consumo.

Os resultados obtidos nas medidas de $\mathrm{pH}$, acidez titulável e contagem de células viáveis nos leites fermentados por Lactobacillus spp. e Bifidobacterium spp. durante 46 dias de estocagem a $7{ }^{\circ} \mathrm{C}$ estão apresentados nas Tabelas 1 e 2, respectivamente.

Todas as culturas mantiveram-se viáveis durante os 46 dias de armazenamento a $7^{\circ} \mathrm{C}$, independentemente de terem sido cultivadas com ou sem mel (Tabelas 1 e 2). Dessa forma, todos os microrganismos atenderam aos parâmetros exigidos pela legislação vigente, que preconiza contagem mínima de $10^{7} \mathrm{UFC} . \mathrm{mL}^{-1}$ para leite acidófilo e $10^{6} \mathrm{UFC} \cdot \mathrm{mL}^{-1}$ para leite fermentado ou cultivado (BRASIL, 2000).

Resultados semelhantes foram relatados por Vinderola et al. (2000) com L. casei, L. acidophilus e bifidobactérias, porém utilizadas no processamento de queijo fresco argentino, relatando sobrevivência satisfatória durante 60 dias, em níveis superiores a $10^{6}$ UFC.g ${ }^{-1}$.

Lankaputhra, Shah e Britz (1996a) e Samona e Robinson, (1991) sugerem que os alimentos ou suplementos contendo probióticos devem conter acima de $10^{5} \mathrm{UFC} \mathrm{g}^{-1}$ durante todo o período de validade do produto. Outros autores sugerem que os produtos fermentados, no momento do consumo, devem conter no mínimo $10^{6} \mathrm{UFC}$. $\mathrm{mL}^{-1}$ células probióticas viáveis, devido à dose mínima terapêutica diária ser de $10^{8}-10^{9}$ células viáveis em $100 \mathrm{~g}$ do produto fermentado. (GOMES; MALCATA, 1999).

O maior número de células viáveis aos 46 dias de armazenamento a $7^{\circ} \mathrm{C}$ foi obtido com linhagens de L. casei com adição de $3 \%$ mel $(\mathrm{p} / \mathrm{v})$ (Tabela 1$)$. Estas bactérias mantiveram seu crescimento constante ao longo dos 46 dias, em torno de 9,21 e 9,16 $\log _{10}$ UFC.mL ${ }^{-1}$, respectivamente, para L. casei-01 e L. casei Shirota. Entretanto, a influência do mel sobre o crescimento e a viabilidade destas culturas não foi significativa $(p>0,05)$.

Resultados semelhantes foram obtidos por Varga (2006) que verificou que a adição de 1,0 e 5,0\% (p/v) de mel em iogurtes refrigerados por 6 semanas a $4^{\circ} \mathrm{C}$ não teve influência significativa nas características sensoriais do produto ou na viabilidade da cultura composta de Streptococcus thermophilus e Lactobacillus delbrueckii subsp. bulgaricus.

Vários fatores como acidificação do produto final, ácidos produzidos durante o armazenamento, nível de oxigênio no produto, permeação do oxigênio através da embalagem, compostos antimicrobianos, e a perda de nutrientes do leite podem reduzir a viabilidade e, conseqüentemente, as propriedades probióticas dos microrganismos (ANDRIGHETTO; GOMES, 2003).

Com o passar dos dias a porcentagem de acidez foi aumentando, mostrando boa capacidade de pós-acidificação, no entanto, sem efeitos inibitórios para a viabilidade celular. Estes dados foram observados para as duas linhagens de L. casei cujos valores de acidez nas fermentações com mel atingiram 1,44 e 1,43\% respectivamente para $L$. casei-01 e L. casei Shirota. Entretanto, não houve inibição do crescimento mesmo nos cultivos de L. casei Shirota, cujos níveis de acidez foram significativamente maiores $(\mathrm{p}<0,05)$ na presença de mel com 35 e 46 dias de armazenamento. Portanto, o mel contribuiu para acelerar o metabolismo (fermentação) sem interferir na viabilidade das células.

Os valores médios de $\mathrm{pH}$ dos cultivos de L c casei com adição de mel foram significativamente menores que dos controles, porém apenas no tempo zero, com valores de 4,47 e 5,25 respectivamente para L. casei-01 e 4,65 e 5,32, para L. casei Shirota (Tabela 1). 
Tabela 1. Valores médios de contagem de placas, acidez titulável e pH obtidos no decorrer do armazenamento (0, 23, 35 e 46 horas) de cultivos de lactobacilos em leite fermentado.

\begin{tabular}{|c|c|c|c|c|c|}
\hline & 0 & 23 & 35 & 46 & Média geral \\
\hline Análises & \multicolumn{5}{|c|}{ Lactobacillus acidophilus Sacco ${ }^{\circledR}$} \\
\hline Contagem de placas com mel (Log UFC.mL $\mathrm{mL}^{-1}$ ) & $8,38^{a}$ & $8,30^{\mathrm{a}}$ & $8,35^{\mathrm{a}}$ & $8,33^{\prime \prime}$ & $8,34^{\mathrm{a}}$ \\
\hline Controle (sem mel) & $8,48^{a}$ & $8,70^{\mathrm{a}}$ & $8,13^{\mathrm{a}}$ & $7,25^{\mathrm{b}}$ & $8,14^{\mathrm{a}}$ \\
\hline Controle (sem mel) & $1,33^{\mathrm{a}}$ & $1,60^{\mathrm{a}}$ & $1,71^{\mathrm{a}}$ & $1,66^{\mathrm{a}}$ & $1,57^{\mathrm{a}}$ \\
\hline pH com mel & $3,64^{2}$ & $3,42^{\mathrm{a}}$ & $3,57^{\mathrm{a}}$ & $3,53^{\mathrm{a}}$ & $3,54^{\mathrm{a}}$ \\
\hline Contagem de placas com mel (Log UFC. $\mathrm{mL}^{-1}$ ) & $8,69^{4}$ & $8,17^{\mathrm{a}}$ & $8,25^{\mathrm{a}}$ & $8,24^{a}$ & $8,34^{\mathrm{a}}$ \\
\hline Controle (sem mel) & $8,60^{\mathrm{a}}$ & $8,36^{\mathrm{a}}$ & $8,29^{\mathrm{a}}$ & $7,45^{\mathrm{a}}$ & $8,18^{\mathrm{a}}$ \\
\hline Acidez titulável com mel (\%) & $0,91^{\mathrm{a}}$ & $1,05^{\mathrm{a}}$ & $1,22^{\mathrm{a}}$ & $1,18^{a}$ & $1,09^{\mathrm{a}}$ \\
\hline Controle (sem mel) & $0,69^{\mathrm{a}}$ & $1,20^{\mathrm{a}}$ & $1,05^{\mathrm{a}}$ & $1,13^{\mathrm{a}}$ & $1,02^{\mathrm{a}}$ \\
\hline $\mathrm{pH}$ com mel & $4,40^{\mathrm{a}}$ & $3,87^{\mathrm{a}}$ & $4,06^{\mathrm{a}}$ & $4,01^{*}$ & $4,08^{\mathrm{a}}$ \\
\hline Acidez titulável com mel (\%) & $0,81^{\mathrm{a}}$ & $1,10^{\mathrm{a}}$ & $1,24^{\mathrm{a}}$ & $1,44^{a}$ & $1,15^{\mathrm{a}}$ \\
\hline Controle (sem mel) & $0,54^{\mathrm{a}}$ & $1,13^{\mathrm{a}}$ & $1,02^{\mathrm{a}}$ & $1,18^{\mathrm{a}}$ & $0,96^{\mathrm{b}}$ \\
\hline $\mathrm{pH}$ com mel & $4,47^{\mathrm{a}}$ & $3,62^{\mathrm{a}}$ & $3,95^{\mathrm{a}}$ & $3,80^{\circ}$ & $3,96^{\mathrm{b}}$ \\
\hline \multirow[t]{2}{*}{ Controle (sem mel) } & $5,25^{\mathrm{b}}$ & $4,06^{\mathrm{a}}$ & $4,18^{\mathrm{a}}$ & $4,03^{\mathrm{a}}$ & $4,38^{\mathrm{a}}$ \\
\hline & \multicolumn{5}{|c|}{ Lactobacillus casei Shirota (Yakult) } \\
\hline Contagem de placas com mel (Log UFC. $\mathrm{mL}^{-1}$ ) & $9,26^{\mathrm{a}}$ & $8,63^{\mathrm{a}}$ & $8,84^{\mathrm{a}}$ & $9,16^{a}$ & $8,97^{\mathrm{a}}$ \\
\hline Controle (sem mel) & $9,18^{\mathrm{a}}$ & $8,71^{\mathrm{a}}$ & $8,77^{\mathrm{a}}$ & $8,86^{a}$ & $8,88^{\mathrm{a}}$ \\
\hline Acidez titulável com mel (\%) & $0,70^{\mathrm{a}}$ & $1,24^{\mathrm{a}}$ & $1,24^{\mathrm{a}}$ & $1,43^{a}$ & $1,15^{\mathrm{a}}$ \\
\hline Controle (sem mel) & $0,38^{\mathrm{a}}$ & $0,94^{\mathrm{a}}$ & $0,84^{\mathrm{b}}$ & $0,85^{\mathrm{b}}$ & $0,75^{\mathrm{b}}$ \\
\hline $\mathrm{pH}$ com mel & $4,65^{\mathrm{a}}$ & $3,73^{\mathrm{a}}$ & $3,85^{\mathrm{a}}$ & $3,80^{\circ}$ & $4,01^{\mathrm{b}}$ \\
\hline
\end{tabular}

Letras diferentes na mesma coluna são significativamente diferentes $(\mathrm{p}<0,05)$ para a mesma análise quando comparada com seu respectivo controle.

Na Tabela 1, pode ser observado que as linhagens de $L$. acidophilus mantiveram a viabilidade em mais de $10^{8}$ UFC. $\mathrm{mL}^{-1}$ durante os 46 dias. Mesmo nos controles sem adição de mel, a população destas linhagens foi superior a $10^{7}$ UFC. $\mathrm{mL}^{-1}$ como preconiza a legislação para leite acidófilo (BRASIL, 2000). Estes resultados foram mais satisfatórios que os obtidos por Bozanic, Rogeli e Tratnik (2001). Estes autores relataram que o $L$. acidophilus permaneceu viável em torno de $10^{6} \mathrm{UFC.g}{ }^{-1}$, por 21 dias de estocagem a $4{ }^{\circ} \mathrm{C}$ em leites fermentados.

Contudo, os resultados obtidos neste estudo, contradizem os de Oliveira et al., (2002) que apontam a perda de viabilidade por esses microrganismos quando estocados por longos dias sob temperatura de refrigeração. Oliveira et al. (2002) relataram a redução de 1,0 ciclo logarítmico nas contagens de L. acidophilus após 28 dias de estocagem a $4{ }^{\circ} \mathrm{C}$ em fermentação apenas com este microrganismo.

Apesar da alta viabilidade das linhagens de L. acidophilus, com exceção do observado no $46^{\circ}$ dia com L. acidophilus Sacco, o mel não estimulou significativamente o crescimento e a manutenção da viabilidade destes probióticos (Tabela 1).
A constante produção de ácidos, chamada também de pósacidificação (OLIVEIRA; DAMIN, 2003), foi principalmente observada para as linhagens de lactobacilos (Tabela 1), enquanto que as linhagens de bifidobactérias apresentaram menor capacidade de pós-acidificação (Tabela 2).

O ácido láctico é o principal produto do metabolismo das bactérias lácticas (cerca de 70 a $90 \%$ dos compostos gerados) e é sintetizado durante todo o processo de fermentação da lactose (FERREIRA, 2003). A produção de ácido lático nos leites fermentados contribui para a desestabilização das micelas de caseína e, conseqüentemente, para a formação do gel, além de proporcionar o seu sabor ácido característico, podendo também acentuar o aroma do produto. Durante a estocagem refrigerada dos produtos lácteos fermentados, pode haver aumento da acidez titulável. Estas mudanças na acidez estão relacionadas com vários fatores, por exemplo: temperatura de refrigeração, tempo de armazenamento e poder de pós-acidificação das culturas utilizadas (GURGEL; OLIVEIRA, 1995).

Nesta pesquisa, pode ser observado, que a maior produção de acidez entre os microrganismos testados, ocorreu com L. acidophilus Sacco ${ }^{\circ}$ que, com 46 dias de estocagem, atingiu $1,64 \%$ de acidez e $\mathrm{pH} 3,53$. Sendo assim, este microrganismo 
Tabela 2. Valores médios de contagem de placas, acidez titulável e pH obtidos no decorrer do armazenamento ( $0,23,35$ e 46 horas) de cultivos de bifidobactérias em leite fermentado.

\begin{tabular}{|c|c|c|c|c|c|}
\hline & 0 & 23 & 35 & 46 & Média geral \\
\hline Análises & \multicolumn{5}{|c|}{ Bifidobacterium BB-12 Christian Hansen ${ }^{\circ}$} \\
\hline Contagem de placas com mel (Log UFC.mL $\left.\mathrm{m}^{-1}\right)$ & $8,12^{\mathrm{a}}$ & $8,09^{\mathrm{a}}$ & $7,84^{\mathrm{a}}$ & $7,63^{\mathrm{a}}$ & $7,92^{\mathrm{a}}$ \\
\hline Controle (sem mel) & $6,71^{\mathrm{a}}$ & $6,93^{\mathrm{a}}$ & $6,60^{\mathrm{a}}$ & $6,11^{\mathrm{a}}$ & $6,59^{\mathrm{b}}$ \\
\hline Acidez titulável com mel (\%) & $0,51^{\mathrm{a}}$ & $0,59^{\mathrm{a}}$ & $0,57^{\mathrm{a}}$ & $0,61^{\mathrm{a}}$ & $0,57^{\mathrm{a}}$ \\
\hline Controle (sem mel) & $0,27^{\mathrm{b}}$ & $0,27^{\mathrm{b}}$ & $0,28^{\mathrm{b}}$ & $0,30^{\mathrm{b}}$ & $0,28^{\mathrm{b}}$ \\
\hline $\mathrm{pH}$ com mel & $4,93^{\mathrm{a}}$ & $5,39^{\mathrm{a}}$ & $5,37^{\mathrm{a}}$ & $4,92^{\mathrm{a}}$ & $5,15^{\mathrm{b}}$ \\
\hline Controle (sem mel) & \multicolumn{5}{|c|}{ Bifidobacterium lactis Sacco ${ }^{\oplus}$} \\
\hline Contagem de placas com mel (Log UFC. $\left.\mathrm{mL}^{-1}\right)$ & $8,94^{\mathrm{a}}$ & $8,61^{\mathrm{a}}$ & $8,73^{\mathrm{a}}$ & $9,11^{a}$ & $8,84^{\mathrm{a}}$ \\
\hline Controle (sem mel) & $8,80^{\mathrm{a}}$ & $8,21^{\mathrm{a}}$ & $8,13^{\mathrm{b}}$ & $8,78^{\mathrm{a}}$ & $8,48^{\mathrm{b}}$ \\
\hline Acidez titulável com mel (\%) & $0,56^{\mathrm{a}}$ & $0,85^{\mathrm{a}}$ & $1,02^{\mathrm{a}}$ & $1,11^{\mathrm{a}}$ & $0,88^{\mathrm{a}}$ \\
\hline Controle (sem mel) & $0,40^{\mathrm{a}}$ & $0,80^{\mathrm{a}}$ & $0,73^{\mathrm{b}}$ & $0,84^{\mathrm{b}}$ & $0,69^{\mathrm{b}}$ \\
\hline $\mathrm{pH}$ com mel & $4,82^{\mathrm{a}}$ & $4,68^{\mathrm{a}}$ & $4,22^{\mathrm{a}}$ & $4,11^{\mathrm{a}}$ & $4,45^{\mathrm{b}}$ \\
\hline Controle (sem mel) & $5,38^{\mathrm{b}}$ & $4,87^{\mathrm{a}}$ & $4,83^{\mathrm{b}}$ & $4,65^{\mathrm{b}}$ & $4,93^{\mathrm{a}}$ \\
\hline
\end{tabular}

Letras diferentes na mesma coluna são significativamente diferentes $(\mathrm{p}<0,05)$ para a mesma análise quando comparada com seu respectivo controle.

possui boas características de adaptação em meios ácidos, já que manteve população de $8,33 \log _{10} \mathrm{UFC} \cdot \mathrm{mL}^{-1}$ durante os 46 dias (Tabela 1).

Não houve diferença significativa de acidez e $\mathrm{pH}$ para ambas as linhagens de L. acidophilus em relação aos seus controles sem mel. Foi observado um aumento constante da acidez e redução do $\mathrm{pH}$ em ambas as fermentações (com e sem mel) até o trigésimo quinto dia, havendo redução dos níveis de acidez com e sem mel no $46^{\circ}$ dia. A acidez não interferiu no crescimento dos lactobacilos, pois, mesmo em níveis elevados, os microrganismos mantiveram sua viabilidade em torno de $8,0 \log _{10}$ UFC.mL ${ }^{-1}$ na presença de mel e em torno de $7,0 \log _{10}$ UFC.mL ${ }^{-1}$ na ausência. Os valores médios de acidez nos leites acidófilos (com e sem adição de mel) atenderam aos parâmetros da legislação, a qual preconiza 0,6-2,0 g de ácido láctico/100 g (BRASIL, 2000) (Tabela 1).

Estudos similares foram realizados por Curda e Plockova (1995), que avaliaram o efeito do mel em concentrações de $(0,1,3,5$ e $10 \%)$ adicionados em leite sobre o crescimento de Lactobacillus acidophilus e cultura de bactérias mesófilas consistindo de Lactococcus lactis subsp lactis, Lactococcus lactis subsp cremoris e Lactococcus lactis subsp lactis biovar diacetylactis, através da técnica de impedância. Os méis receberam tratamentos diferentes. Um foi esterilizado a $121^{\circ} \mathrm{C}$ por 15 minutos e o outro não recebeu tratamento algum. Os resultados revelaram que $L$. acidophilus foi inibido em concentrações superiores a $5 \%$ de mel, independente do tratamento, enquanto as culturas mesófilas foram inibidas somente pela concentração $10 \%$ de mel não tratado, não sendo inibidas por nenhuma das concentrações de mel esterilizado.

Resultados diferentes foram encontrados por Barreto et al. (2003), que avaliaram a viabilidade de Lactobacillus acidophilus, bifidobactérias e bactérias totais em 177 amostras de 15 marcas de produtos probióticos comercializados no Brasil. Em $52 \%$ dos produtos contendo o probiótico L. acidophilus, as contagens estavam abaixo de $10^{5} \mathrm{UFC}^{\mathrm{g}} \mathrm{g}^{-1} \mathrm{e}$, em $64 \%$ das amostras, apresentaram contagens de bifidobactérias abaixo de $10^{5} \mathrm{UFC} \cdot \mathrm{g}^{-1}$.
Considerando todo o período de estocagem, o mel exerceu efeito positivo significativo $(\mathrm{p}<0,05)$ sobre as culturas de Bifidobacterium, diferentemente do que ocorreu com Lactobacillus spp. A média geral do crescimento e da viabilidade das linhagens de Bifidobacterium foi significativamente maior $(\mathrm{p}<0,05)$ comparada aos seus respectivos controles (sem mel) (Tabela 2).

Os resultados obtidos nesta pesquisa corroboram aqueles relatados por Kajiwara, Gandhi e Ustunol (2002) que verificaram o crescimento de bifidobactérias em meio de cultura suplementado com $5 \%$ de mel por 48 horas de incubação a $37^{\circ} \mathrm{C}$ sob anaerobiose. Esses autores relataram que houve aumento do crescimento das culturas suplementadas com mel ou oligossacarídeos.

Ustunol e Gandhi (2001) verificaram a viabilidade de linhagens de Bifidobacterium spp. em leites adicionados de mel, sacarose, frutose ou glicose. Os resultados obtidos pelos autores revelaram que a viabilidade de Bifidobacterium spp. foi maior comparada aos controles dos açúcares comerciais, por um período de apenas 14 dias de estocagem refrigerada. Um intervalo bem menor que os 46 dias observados nesta pesquisa (Tabela 2).

Os menores valores quanto ao número de células viáveis com 46 dias foram encontrados para Bifidobacterium BB-12, que passou de $8,12 \log _{10}$ UFC.mL $L^{-1}$ no tempo zero para 7,63 após 46 dias de armazenamento nos cultivos com mel e de 6,71 a 6,11 $\log _{10}$ UFC.mL $L^{-1}$ nos cultivos sem mel (Tabela 2).

Por outro lado, nos cultivos de Bifidobacterium lactis $\mathrm{Sacco}^{\circ}$ não foi detectada redução da viabilidade. $\mathrm{O}$ número de células viáveis passou de $8,94 \log _{10} \mathrm{UFC} \cdot \mathrm{mL}^{-1}$ no tempo zero para 9,11 , após 46 dias de armazenamento nos cultivos com mel, e de 8,80 a $8,78 \log _{10}$ UFC.mL $L^{-1}$ nos cultivos sem mel. Aos 46 dias de estocagem a $7^{\circ} \mathrm{C}$, o pH destes cultivos foi de 4,11 e $1,11 \%$ de acidez (Tabela 2). Portanto, esta linhagem possui grande capacidade de adaptação em $\mathrm{pH}$ reduzido e níveis altos de acidez. Entretanto a linhagem Bb-12, apesar de ser da mesma 
espécie, teve comportamento diferente. Dessa forma, conclui-se que a seleção de linhagens específicas é de suma importância para a utilização em produtos probióticos. Esses dados corroboram aqueles relatados por Gomes, Malcata e Klaver (1998a) e Gomes, Teixeira e Malcata (1998b). Estes autores relataram que algumas espécies de bifidobactérias de origem animal são mais facilmente cultivadas e podem resistir ao baixo $\mathrm{pH}$ como também a baixos níveis de oxigênio. Citam ainda que a $B$. lactis é considerada uma das mais promissoras, pois possui boa tolerância ao oxigênio e ao ácido.

Os oligossacarídeos exercem efeitos comprovadamente prebióticos sobre a microbiota benéfica intestinal. Com esse intuito, Villaluenga et al. (2006) avaliaram a influência da rafinose, um trissacarídeo, sobre a sobrevivência de Bifidobacterium lactis Bb-12 e Lactobacillus acidophilus La-5 em leites fermentados durante 21 dias refrigerados a $4{ }^{\circ} \mathrm{C}$. A Bifidobacterium lactis $\mathrm{Bb}-12$ provou ser mais sensível que o L. acidophilus La-5. O aumento da resistência dos probióticos à temperatura de $4{ }^{\circ} \mathrm{C}$ foi mostrado na presença de rafinose, com médias de aproximadamente $7 \log _{10}$ células viáveis com 21 dias e 6,2 $\log _{10}$ sem a rafinose.

$\mathrm{Na}$ Tabela 2, pode ser observado que no $35^{\circ}$ dia de armazenamento a $7{ }^{\circ} \mathrm{C}$, tanto os resultados das contagens como os de acidez titulável e de $\mathrm{pH}$ obtidos com Bf. lactis Sacco ${ }^{\varpi} \mathrm{em}$ presença de mel foram significativamente diferentes $(\mathrm{p}<0,05)$ dos obtidos nos controles. Estes resultados comprovam que esta cultura apresenta boa tolerância à acidez, já que o metabolismo mais acentuado em presença de mel não interferiu e até estimulou o crescimento.

A cultura Bifidobacterium Bb-12 apresentou maior sensibilidade à acidez. Embora os resultados de acidez titulável nos tempos, 0, 23, 35 e 46 tenham sido significativamente maiores $(\mathrm{p}<0,05)$ nos cultivos adicionados de mel comparados aos controles sem mel, não foi detectada diferença significativa ( $p>0,05)$ no crescimento (Tabela 2). A acidez foi aumentando ao longo dos 46 dias, porém os valores obtidos não atendem à legislação, a qual estabelece valores de 0,6-2,0 g de ácido láctico/100 g (BRASIL, 2000) e somente no quadragésimo sexto dia a acidez produzida na fermentação com mel atendeu aos parâmetros da legislação, com o valor de 0,61\% (Tabela 2).

O mel, por conter um alto teor de carboidratos fermentáveis, propicia maior produção de ácido e conseqüente abaixamento do $\mathrm{pH}$. Os valores médios de $\mathrm{pH}$ obtidos nos cultivos de Bifidobacterium Bb-12 em presença de mel foram significativamente diferentes dos controles sem mel $(\mathrm{p}<0,05)$, mas não afetaram a viabilidade deste probiótico (Tabela 2).

As bifidobactérias possuem baixa capacidade de acidificação durante o processo de pós-acidificação na estocagem (GOMES; MALCATA, 1999). Os relatos desses autores corroboram os dados observados nesta pesquisa com as duas linhagens de bifidobactérias, principalmente por Bifidobacterium Bb-12 Christian Hansen.

Segundo Rasic e Kurmann (1983) e Danone (1997), os valores ótimos de $\mathrm{pH}$ para o crescimento de bifidobactérias estão entre $6,0-7,0$, com ausência de crescimento em valores de $\mathrm{pH}$ ácidos de 4,5-5,0.
Chick, Shin e Ustinol (2001) avaliaram a influência do mel e outros açúcares quanto à acidez e viabilidade de quatro culturas: Streptococcus thermophilus, Lactobacillus acidophilus, Lactobacillus delbrukeii subsp bulgaricus, e Bifidobacterium bifidum. Os microrganismos foram inoculados em leite reconstituído $12 \%$ suplementado com 5\% de mel, 5\% de frutose e 5\% de sacarose, separadamente. As amostras foram analisadas nos tempos 0 e 24 horas. Todas as culturas permaneceram viáveis na presença de mel e nos outros açúcares, porém a viabilidade não foi significativamente diferente entre os meios. A adição de $5 \%$ de mel nos leites não foi inibitória para as culturas. A produção de ácido láctico pela Bifidobacterium bifidum foi significativamente maior na presença de mel, quando comparada com outros açúcares. Segundo os dados obtidos, os autores descartaram a hipótese de que a frutose presente no mel possa ser um fator contribuinte para o aumento da produção de ácido láctico, sugerindo que os oligossacarídeos presentes no mel são os responsáveis pelo aumento da produção de ácido láctico.

Em estudo realizado por Ustunol (2005), foi verificado que a adição de 3 e $5 \%$ de mel em leites fermentados por Bifidobacterium Bf-1 e Bifidobacterium Bf-6 Bifidobacterium infantis (Rhone Poulenc Inc.), Bifidobacterium infantis (Chr. Hansen) Bifidobacterium longum e Bifidobacterium bifidum, aumentaram a taxa de crescimento durante a fermentação e a viabilidade quando comparados com o controle e outros açúcares na maioria das linhagens. Foi também comparado com oligossacarídeos comerciais, como inulina, frutooligossacarídeo e galactooligossacarídeo. A viabilidade foi testada durante 28 dias sob refrigeração a $4{ }^{\circ} \mathrm{C}$. O autor concluiu que a influência do mel no crescimento e viabilidade é específica para cada linhagem e que não houve diferença significativa no crescimento das seis linhagens na presença de mel comparado com oligossacarídeos comerciais.

Zacarchenco e Massaguer-Roig (2004) avaliaram o pH, acidez titulável e contagens de células viáveis de três leites fermentados armazenados por 21 dias a $4{ }^{\circ} \mathrm{C}$. A maior acidez e menor $\mathrm{pH}$ foram obtidos no leite fermentado por Str. thermophilus, enquanto o leite fermentado por Bif. longum apresentou a menor acidez e o maior $\mathrm{pH}$. A contagem de células viáveis de Str. thermophilus foi de $10^{9}$ e $10^{8}$ UFC. $\mathrm{mL}^{-1}$ e Bif. longum de $10^{8}$ UFC. $\mathrm{mL}^{-1}$, e tanto no leite fermentado elaborado pela mistura como nos isolados mantiveram-se constantes até 21 dias de estocagem.

Por outro lado, Lankaputhra, Shah e Britz (1996b) relataram que a viabilidade de Bifidobacterium infantis em leite reconstituído $12 \%$ a pH 4,3 mostrou uma diminuição de $30 \%$ no crescimento com 12 dias de estocagem a $4{ }^{\circ} \mathrm{C}$ e mais de $82 \%$ de redução com 24 dias.

\section{Conclusões}

Todos os cultivos, independentemente de terem sido adicionados de mel, mantiveram-se viáveis por 46 dias a $7^{\circ} \mathrm{C}$ com número mínimo de células viáveis exigidos pela legislação. Embora com crescimento absoluto menor que dos lactobacilos, o metabolismo das duas linhagens de bifidobactérias foi estimulado, mostrando resposta positiva frente ao mel. Estas 
linhagens também mostraram uma capacidade de adaptação em $\mathrm{pH}$ reduzido e altos níveis de acidez maior que aquela normalmente aceita como limite para crescimento de bactérias bífidas, especialmente a linhagem $B f$. lactis Sacco ${ }^{\circ}$. Não foi observado declínio significativo nas contagens durante o armazenamento tanto para lactobacilos como para bifidobactérias com exceção do cultivo de $L$. acidophilus $\mathrm{Sacco}^{\circ}$ sem mel, que, no final do período, estava um ciclo log menor que nos cultivos com mel.

\section{Referências bibliográficas}

ANDRIGHeTtO, C.; GOMES, M. I. F. V. Produção de picolés utilizando leite acidófilo. Brazilian Journal of Food Technology, v. 6, n. 2, p. 267-271, 2003.

ANJO, D. F. C. Alimentos funcionais em angiologia e cirurgia vascular. Jornal Vascular Brasileiro, v. 3, n. 2, p. 145-154, 2004.

BARRETO, G. P. M. et al. Quantificação de Lactobacillus acidophilus, bifidobactérias e bactérias totais em produtos probióticos comercializados no Brasil. Brazilian Journal of Food Technology, v. 6, n. 1, p. 119-126, 2003.

BOYLSTON, T. D. et al. Incorporation of bifidobacteria into cheeses: challenges and rewards. International Dairy Journal, v. 14, n. 5, p. 375-387, 2004.

BOZANIC, R.; ROGELI, I.; TRATNIK, L. J. Fermented acidophilus goat's milk supplemented with inulin: comparison with cow's milk. Milchwissenchaft, v. 56, n. 11, p. 618-622, 2001.

BRANDÃO, S. C. C. Novas gerações de produtos lácteos funcionais. Indústria de Laticínios, v. 6, n. 37, p. 64-66, 2002.

BRASIL.MINISTÉRIODA AGRICULTURAEDOABASTECIMENTO. Resolução n. 5, de 13 de novembro de 2000. Padrões de identidade e qualidade de leites fermentados. Diário Oficial da União, Brasília, DF, 02 jan. 2001, Seção I, p. 19-22.

CHICK, H.; SHIN, H. S.; USTUNOL, Z. Growth and acid production by lactic acid bacteria and bifidobacteria grown in skim milk containing honey. Journal of Food Science, v. 66, n. 3, p. 478-481, 2001.

CRITTENDEN, R. G., PLAYNE, M. J. Production, properties and applications of food-grade oligosaccharides. Trends in Food Science \& Technology, v. 7, n. 11, p. 353-361, 1996.

CURDA, L.; PLOCKOVA, M. Impedance measurement of growth of lactic acid bacteria in dairy cultures with honey addition. International Dairy Journal, v. 5, n. 7, p. 727-733, 1995.

DANONE WORLD NEWSLETTER. Bifidobacteria. Newsletter, n. 16, nov. 1997. Disponível em: <http://www.danonevitapole. com/nutri_views/newsletter/eng/news_16/sum.html >. Acesso em: 02 jul. 2006.

FEDERAÇÃO INTERNATIONAL DE LATICÍNIOS 150:1991. Yogurt: determination de l'acidity titratable (methode que). Bruxelles, 1991.

FERREIRA, C. L. L. F. Prebióticos e probióticos: atualização e prospecção. Viçosa: Suprema Gráfica e Editora Ltda, 2003. 205 p.

FERREIRA, C. L. L. F. Produtos lácteos de terceira geração: importância de produtos contendo bactérias bífidas. Leite \& Derivados, n. 29, p. 22-28, 1996.

FONDÉN, R. et al. Effect of culture-containing dairy products on intestinal microflora, human nutrition and health - current knowledge and future perspectives. Bulletin FIL-IDF (Belgium) International Dairy Federation, n. 352, p. 5-30, 2000.
GOMES, A. M. P.; MALCATA, F. X. Bifidobacterium spp. and Lactobacillus acidophilus: biological, biochemical, technological and therapeutical properties relevant for use as probiotics. Trends in Food Science \& Technology, v. 10, n. 4-5, p. 139-157, 1999.

GOMES, A. M. P.; MALCATA, F. X.; KLAVER, F. A. M. Growth enhancement of Bifidobacterium lactis Bo and Lactobacillus acidophilus Ki by milk hydrolyzates. Journal of Dairy Science, v. 81, n. 11, p. 2817-2825, 1998a.

GOMES, A. M. P.; TEIXEIRA, M. G.; MALCATA, F. X. Viability of Bifidobacterium lactis and Lactobacillus acidophilus in milk: sodium chloride concentration and storage temperature. Journal of Food Processing and Preservation, v. 22, n. 3, p. 221-240, 1998b.

GONNET, M.; LAVIE, P.; LOUVEAUX, J. La pasteurization des miels. In Annals of Abeilles, v. 7, n. 2, p. 81-102, 1964.

GURGEL, M. S. C. C. A.; OLIVEIRA, A. J. Avaliação das características físico-químicas do iogurte. Leite \& Derivados, v. 4, n. 22, p. 38-43, 1995.

HOLZAPFEL, W. H.; SCHILLINGER, U. Introduction to pre and probiotics. Food Research International, v. 35, n. 2-3, p. 109-116, 2002.

KAILASAPATHY, K.; RYBKA, S. L. acidophilus and Bifidobacterium spp. - their therapeutic potential and survival in yoghurt. The Australian Journal of Dairy Technology, v. 52, n. 1, p. 28-35, 1997.

KAJIWARA, S.; GANDHI, H.; USTUNOL, Z. Research Note: Effect of Honey on the Growth of and Acid Production by Human Intestinal Bifidobacterium spp.: An In Vitro Comparison with Commercial Oligosaccharides and Inulin. Journal of Food Protection, v. 65, n. 1, p. 214-218, 2002.

KANDLER, O.; WEISS, N. 1986. Genus Lactobacillus Beijerinck 1901, 212AL. In: SNEATH, P. H. A.; MAIR, N. S.; SHARPE, M. E. and HOLT, J. G. (eds). Bergey's Manual of Systematic Bacteriology. Baltimore: Williams \& Wilkins.

KURMANN, J. A. Starters with selected intestinal bacteria. Fermented milks: Science and technology. Bulletin on the Intestinal Dairy Federation, n. 227, p. 41-55, 1988.

LANKAPUTHRA, W. E. V.; SHAH, N. P.; BRITZ, M. L. Evaluation of media for selective enumeration of Lactobacillus acidophilus and Bifidobacterium species. Food Australia, v. 48, n. 3, p. 113-118, 1996a.

LANKAPUTHRA, W. E. V.; SHAH, N.; BRITZ, M. Survival of bifidobacteria during refrigerated storage in presence of acid and hydrogen peroxide. Milchwissenschaft, v. 51, n. 2, p. 65-70, 1996b.

LEITE, J. M. C. et al. Determination of oligosaccharides in Brazilian honeys of different botanical origin. Food Chemistry, v. 70, n. 1, p. 93-98, 2000.

NAKANO, H. Recent Japanese development in the enzymatic production and application of oligosaccharides, presented at??? In: Seminar on enzyme and bacterial technology. Campinas: Japan International Cooperation Agency, 1998.

OLIVEIRA, M. N.; DAMIN, M. R. Efeito do teor de sólidos e da concentração de sacarose na acidificação, firmeza e viabilidade de bactérias do iogurte e probióticas em leite fermentado. Ciência e Tecnologia de Alimentos, v. 23, supl, p. 172-176, 2003.

OLIVEIRA, M. N. et al. Manufacture of fermented lactic beverages containing probiotic cultures. Journal of Food Science, v. 67, n. 6, p. 2336-2341, 2002.

RASIC, J. L.; KURMAN, J. A. Bifidobacteria and Their Role. Basel: Birklhäuser Verlag, 1983. 295p 
ROBERFROID, M.; SLAVIN, J. Nondigestible oligosaccharides. Critical Reviews in Food Sceince and Nutrition, v. 40, n. 6, p. 461-480, 2000.

SAAD, S. M. I. Probiotics and prebiotics: the state of the art. Revista Brasileira de Ciências Farmacêuticas, v. 42, n. 1, p. 1-16, 2006.

SAARELA, M. et al. Probiotic bacteria: safety, functional and technological properties. Journal of Biotechnology, v. 84, n. 3, p. 197-215, 2000.

SAMONA, A.; ROBINSON, R. K. Enumeration of bifidobacteria in dairy products. Journal of the Society of Dairy Technology, v. 44, n. 3, p. 64-66, 1991.

SHAH, N. P. Probiotic bacteria: selective enumeration and survival in dairy foods. Journal of Dairy Science, v. 83, n. 4, p. 894-907, 2000.

SHAH, N. P. et al. Survival of Lactobacillus acidophilus and Bifidobacterium bifidum in commercial yoghurt during refrigerated storage. International Dairy Journal, v. 5, n. 5, p. 515-521, 1995.

TAMIME, A. Y.; MARSHALL, V.M.E.; ROBINSON, R. K. Microbiological and technological aspects of milks fermented by bifidobacteria. Journal of Dairy Research, v. 62, n. 1, p. 151-187, 1995.
USTUNOL, Z. The effect of honey on the growth of bifidobacteria. National Honey Board. Disponível em: <http.:/www.nhb.org.htm >. Acesso em: 15 mar. 2005.

USTUNOL, Z.; GANDHI, H. Growth and Viability of Commercial Bifidobacterium spp. in Honey-Sweetened Skim Milk. Journal of Food Protection, v. 64, n. 11, p. 1775-1779, 2001.

VARGA, L. Effect of acacia (Robinia pseudo-acacia L.) honey on the characteristic microflora of yogurt during refrigerated storage. International Journal of Food Microbiology, v. 108, n. 2, p. 272-275, 2006.

VILLALUENGA, C. M. et al. Influence of addition of raffinose family oligosaccharides on probiotic survival in fermented milk during refrigerated storage. International Dairy Journal, v. 16, n. 7, p. 768-774, 2006.

VINDEROLA, C. G. et al. Viability of probiotic (Bifidobacterium, Lactobacillus acidophilus and Lactobacillus casei) and non probiotic microflora in Argentinian fresco cheese. Journal Dairy Science, v. 83, n. 9, p. 1905-1911, 2000.

ZACARCHENCO, P. B.; MASSAGUER-ROIG, S. Avaliação sensorial, microbiológica e de pós-acidificação durante a vida de prateleira de leites fermentados contendo Streptococcus thermophilus, Bifidobacterium longum e Lactobacillus acidophilus. Ciência e Tecnologia de Alimentos, v. 24, n. 4, p. 674-679, 2004. 